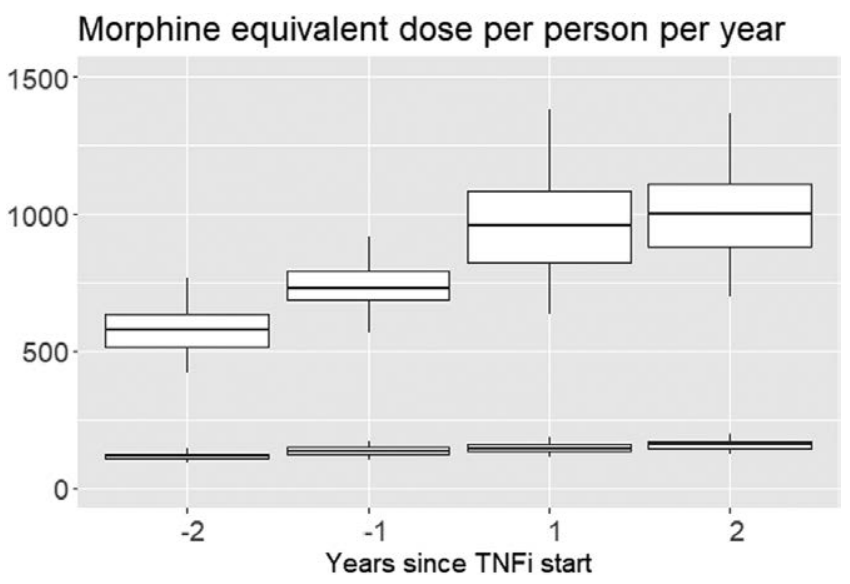

Figure 2. Bootstrapped mean oral morphine equivalent dose per person per year for patients with inflammatory arthritis (above) and age and sex matched comparators (below). Box edges represent $25-75^{\text {th }}$ percentiles and whiskers $95 \%$ confidence intervals.

Table 1. Baseline demographic data. Mean \pm SD unless specified. * defined from diagnosis to baseline.

\begin{tabular}{lccccc}
\hline & All patients & $\begin{array}{c}\text { Rheumatoid } \\
\text { arthritis }\end{array}$ & $\begin{array}{c}\text { Psoriatic } \\
\text { arthritis }\end{array}$ & $\begin{array}{c}\text { Ankylosing } \\
\text { spondylitis }\end{array}$ & $\begin{array}{c}\text { Undifferentiated } \\
\text { arthritis }\end{array}$ \\
\hline $\begin{array}{l}\text { Total n (\%) } \\
\text { Age (years) }\end{array}$ & $940(100)$ & $359(38)$ & $251(27)$ & $217(23)$ & $113(12)$ \\
$\begin{array}{l}\text { Disease duration } \\
\text { (years) }^{*}\end{array}$ & $7.8 \pm 8.5$ & $83 \pm 14$ & $49 \pm 13$ & $43 \pm 13$ & $44 \pm 15$ \\
Female & $58 \%$ & $73 \%$ & $59 \%$ & $34 \%$ & $52 \%$ \\
\hline
\end{tabular}

Disclosure of Interests: Olafur Palsson: None declared, Thorvardur Love: None declared, Johan K Wallman Consultant of: Consultant for AbbVie, Celgene, Eli Lilly, Novartis and UCB Pharma., Meliha C Kapetanovic: None declared, Petur S Gunnarsson: None declared, Björn Gudbjornsson Speakers bureau: Novartis and Amgen

DOI: 10.1136/annrheumdis-2020-eular.2587

\section{OP0089 EFFICACY OF CLOMIPRAMINE FOR CHRONIC LUMBAR RADICULAR PAIN A RANDOMIZED CLINICAL TRIAL}

S. Afilal ${ }^{1}$, S. Fellous ${ }^{1}$, A. Ilham ${ }^{1}$, R. Abouqal ${ }^{2}$, I. Hmamouchi ${ }^{2,3}$, N. Alami ${ }^{1}$, T. Latifa ${ }^{1}$, H. Rkain ${ }^{1,4}$, F. Allali' ${ }^{1}{ }^{1}$ El Ayachi Hospital, Faculty of Medicine and Pharmacy of Rabat, Mohammed V University, Rabat, Morocco;

${ }^{2}$ Laboratory of Biostatistics, Clinical Research and Epidemiology, Faculty of Medicine and Pharmacy Rabat, Rabat, Morocco; ${ }^{3}$ Rheumatology Unit, Provincial Hospital Temara, Temara, Morocco; ${ }^{4}$ Laboratory of Physiology, Faculty of Medicine and Pharmacy of Rabat, Mohammed V University, Rabat, Morocco

Background: Lumbar radicular pain is the most common chronic neuropathic pain syndrome. Antidepressants are highly recommended for neuropathic pain, but there is no evidence for their efficacy.

Objectives: The aim of this double-blind, randomised, placebo-controlled trial is to determine whether Clomipramine (an antidepressant) is more effective than placebo in reducing pain in individuals with resistant chronic lumbar radicular pain.

Methods: A double-blind, randomized, clinical trial. Sixty-two patients with resistant chronic lumbar radicular pain were included. (The sample size was calculated on the assumption that clomipramine would reduce the incidence of lumbar radicular pain of $35 \%$, compared with placebo, with a two-sided test, an alpha level of 0.05 , and a power of $85 \%$ ). Patients were randomly allocated to receive either Clomipramine by slow intravenous infusion for 10 days in a hospital setting with progressively increasing doses, $25 \mathrm{mg}$ on the first day, $50 \mathrm{mg}$ on the second day and $75 \mathrm{mg}$ on the third day until the tenth day, or placebo $(500 \mathrm{ml}$ of physiological serum a day). For both groups, paracetamol is added intravenously at a dose of $3 \mathrm{~g}$ per day for ten days, Parecoxib for 3 days and ten sessions of lumbar spine rehabilitation including analgesic massage, muscle strengthening and joint maintenance. At the exit, clomipramine was relayed with $25 \mathrm{mg}$ per day orally until the 90th day for clomipramine group, and paracetamol was authorized in both groups, in case of severe pain. The primary outcome was pain intensity, measured at baseline, 5 th day, 10th day and 90th day using VAS pain $(10 \mathrm{~mm})$. Secondary outcome included DN4-questionnaire, lumbar radicular discomfort (VAS $10 \mathrm{~mm}$ ), painfree perimeter of walking ( $\mathrm{min}$ ), disability assessed using the Roland Morris Disability questionnaire and severity of mood symptoms assessed using the Hospital Anxiety and Depression scale (HAD), measured on days 0, 5, 10 and 90 .

Results: 31 patients were assigned to the clomipramine group and 31 to the placebo group. There were no differences between the groups in demographic characteristics. Treatment by Clomipramine had a significantly greater reduction in pain, discomfort and DN4 from the $5^{\text {th }}$ day $(p=0.000, p$ $=0.001$ and $p=0.004$ respectively) than the placebo, with an improvement maintained until 90th day. There was a statistically significant improvement in pain-free walking distance and disability for the clomipramine group from the $10^{\text {th }}$ day ( $p=0.02$ and 0.001 respectively) and that maintained until $90^{\text {th }}$ day. However, there was no significant improvement in HAD between the 2 groups. $(p \geq 0.1)$.

Conclusion: This double-blind, randomized, clinical trial shows that clomipramine is quickly effective and maintained over time in the management of resistant chronic lumbar radicular pain. It can therefore be part of the therapeutic arsenal in this sense.

Disclosure of Interests: None declared

DOI: 10.1136/annrheumdis-2020-eular.4373

\begin{tabular}{|l|l}
\hline OP0090 & EFFICACY OF SUBCUTANEOUS TANEZUMAB FOR \\
THE TREATMENT OF CHRONIC LOW BACK PAIN: \\
AN ANALYSIS OF BRIEF PAIN INVENTORY-SHORT \\
FORM SCORES FROM A 56-WEEK, RANDOMIZED, \\
PLACEBO- AND TRAMADOL-CONTROLLED, \\
PHASE 3 TRIAL
\end{tabular}

J. Markman ${ }^{1}$, S. Perrot ${ }^{2}$, S. Ohtori ${ }^{3}$, T. Schnitzer ${ }^{4}$, S. Beydoun ${ }^{5}$, L. Viktrup ${ }^{6}$ R. Yang ${ }^{7}$, C. Bramson ${ }^{8}$, C. West ${ }^{8}$, K. Verburg ${ }^{8} .{ }^{1}$ University of Rochester Medical Center, Rochester, United States of America; ${ }^{2}$ Paris Descartes University, Paris, France; ${ }^{3}$ Chiba University, Chiba, Japan; ${ }^{4}$ Northwestern University Feinberg School of Medicine, Chicago, United States of America; ${ }^{5}$ University of Southern California, Los Angeles, United States of America; ${ }^{6}$ Eli Lilly \& Company, Indianapolis, United States of America; ${ }^{7}$ Pfizer Inc, New York, United States of America; ${ }^{8}$ Pfizer Inc, Groton, United States of America

Background: Tanezumab, a monoclonal antibody against nerve growth factor, was recently evaluated in an 80 week placebo and tramadol-controlled trial in patients with chronic low back pain (CLBP) and a history of inadequate response to standard-of-care analgesics (NSAIDs, opioids, etc). Primary endpoint was change in Low Back Pain Intensity (LBPI) at week 16 vs placebo. Key secondary endpoints were the proportion of patients with $\geq 50 \%$ improvement in LBP at week 16, change in Roland Morris Disability Questionnaire score at week 16, and change in LBPI at week 2 (all vs placebo). Tanezumab $10 \mathrm{mg}$ met the primary and all key secondary endpoints. Tanezumab $5 \mathrm{mg}$ did not meet the primary endpoint, but improved 2 of 3 key secondary endpoints. Due to the primary endpoint result and the statistical gate-keeping approach to control for multiple comparisons, a conclusion of superiority over placebo could not be made for the $5 \mathrm{mg}$ dose.

Objectives: To further characterize tanezumab's effects on pain and function in this trial through analysis of Brief Pain Inventory-short form (BPI-sf) scores. Methods: Patients received placebo $(n=406)$, subcutaneous (SC) tanezumab $5 \mathrm{mg}$ (every 8 weeks; $\mathrm{n}=407$ ), SC tanezumab $10 \mathrm{mg}$ (every 8 weeks; $n=407$ ) or oral tramadol prolonged-release (100-300mg/day; $n=605)$. Pre-specified secondary endpoints included BPI-sf worst pain, average pain, the overall pain interference index, and selected individual domains of the index (general activity, walking ability, sleep, and normal work). Least squares (LS) mean (standard error [SE]) changes from baseline in BPI-sf scores were compared between groups (unadjusted for multiplicity) at week 16 using an analysis of covariance model. Scores range from 0-10 with higher scores indicating greater pain severity or functional impairment.

Results: LS mean (SE) differences from placebo for worst pain were -0.52 $(0.19)$ for tanezumab $5 \mathrm{mg}(p \leq 0.01),-0.54(0.19)$ for tanezumab $10 \mathrm{mg}(\leq 0.01)$, and -0.24 $(0.17)$ for tramadol $(\mathrm{p}=0.17)$. LS mean (SE) differences from placebo for average pain were $-0.37(0.18)$ for tanezumab $5 \mathrm{mg}(\mathrm{p}=0.04),-0.46(0.18)$ for tanezumab $10 \mathrm{mg}(\leq 0.01)$, and $-0.17(0.16)$ for tramadol $(\mathrm{p}=0.29)$. LS mean (SE) differences from placebo for the pain interference index were $-0.41(0.18)$ for tanezumab $5 \mathrm{mg}(\mathrm{p}=0.03),-0.58(0.18)$ for tanezumab $10 \mathrm{mg}(\leq 0.01)$, and $-0.15(0.17)$ fo tramadol $(p=0.39)$. Effects of tanezumab were not statistically different $(p>0.05)$ 